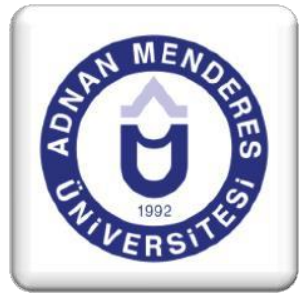

\section{Türkiye'de Finansal Gelişme ve Ekonomik Büyüme Bağlantısı: Bootstrap Yaklaşımına Dayalı Nedensellik Analizi ${ }^{1}$}

\author{
Harun BAL ${ }^{2}$, Emrah Eray AKÇA ${ }^{3}$, Müge MANGA ${ }^{4}$
}

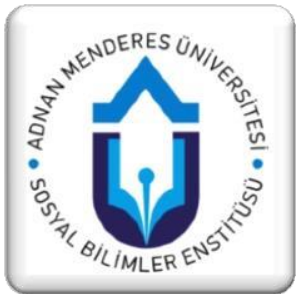

\title{
ÖZET
}

Bu çalışmada Türkiye için 1986-2016 dönemi yıllık zaman serileri kullanılarak finansal gelişme ve ekonomik büyüme arasındaki ilişkinin belirlenmesine yönelik nedensellik analizleri yürütülmüştür. Nedensellik ilişkisinin test edilmesinde Hacker ve Hatemi-J (2006) tarafından geliştirilen Kaldıraçlı (Leveraged) Bootstrap yaklaşımı prosedürü takip edilmiştir. Nedensellik analizlerinden elde edilen bulgular genel olarak nedenselliğin yönünün finansal gelişmeden ekonomik büyümeye doğru olduğuna işaret etmektedir. Elde edilen bulgular, Türkiye'de mevcut zaman diliminde, ağırlıklı olarak Arz Öncüllü Hipotez'in desteklendiğini göstermektedir. Dolayısıyla Türkiye'de finansal gelişmeyi artırmaya dönük uygulamaların ekonomik büyümeye pozitif yönde katkı sunduğu ve bu tür uygulamaların kontrollü ve dikkatli bir şekilde geliştirilmesi gerekliliği çalışmadan elde edilen temel çıkarımdır.

Anahtar Kelimeler: Finansal Gelişme, Ekonomik Büyüme, Bootstrap Yaklaşımı, Türkiye

\section{Financial Development and Economic Growth Nexus In Turkey: Casuality Analysis Based On Bootsrap Approach}

\begin{abstract}
In this study, causality analysis were carried out to specify the relationship between financial development and economic growth using annual data for 1986-2016 period for Turkey. It was followed Leveraged Bootstrap Approach Procedure by Hacker and Hatemi-J (2006) to test causality. Findings obtained from causality analysis generally refer to one-way causality towards economic growth from financial development. General results obtained from our study support evidence on supply-leading hypothesis. Consequently, practices towards financial development contribute positively to economic development. Therefore, these practices should be improved in carefull and in a controlled manner.
\end{abstract}

Keywords: Financial Development, Economic Growth, Bootstrap Approach, Turkey

\footnotetext{
${ }^{1} \mathrm{Bu}$ çalışma 9-11 Kasım 2017 tarihlerinde Ankara'da düzenlenen Uluslararası Politik, Ekonomik ve Sosyal Araştırmalar Kongresi'nde özet bildiri olarak sunulmuştur.

${ }^{2}$ Prof., Çukurova Üniversitesi, İ.İ.B.F. İktisat Bölümü, harunbal@cu.edu.tr

${ }^{3}$ Arş. Gör., Çukurova Üniversitesi, İ.İ.B.F. İktisat Bölümü, eakca@cu.edu.tr

${ }^{4}$ Dr. Öğr. Üyesi , Erzincan Üniversitesi, İ.İ.B.F. İktisat Bölümü, mmanga@erzincan.edu.tr
} 


\section{Giriş}

Ülke ekonomisinde para ve sermaye piyasalarında görülen serbestleşme hareketlerinin işlevselliği, bu piyasalara aracılık eden kurum ve kuruluşların niceliksel/niteliksel özellikleri ile paralellik göstermektedir. Finansal sistemi oluşturan kurum ve kuruluşlar, özellikle finansal risklerin azaltılmasını, ticaretin korunmasını ve çeşitlendirilmesini sağlamaktadır. $\mathrm{Bu}$ sayede finansal sisteme aracılık eden kurum ve kuruluşlar kaynakların tahsisini ve yapılan işlemlere aracılık eden yöneticilerin kurumsal kontrolünü sağlayarak mal ve hizmetlerin etkin bir şekilde el değiştirmesine ve ekonomik büyümenin sağlanmasına ön ayak olurlar (Levine, 1997). Finansal gelişme ve ekonomik büyüme arasındaki ilişki üzerine yapılan çalışmalardaki genel görüş, iyi işleyen finansal bir sistemin ekonomik büyümenin sağlanmasında önem arz edeceği yönündedir. Bu doğrultuda 1960'lı y1llarda yerli finansal yapının ekonomik büyüme üzerindeki etkileri incelenmiş, 1970'li yıllarda finansal sektör politikaları üzerinde yoğunlaşılmış, 1980'li yıllarda ise neoklasik büyüme modellerinin etkisinin azalması dolayısıyla içsel büyüme teorileri ile finansal gelişmenin ekonomik büyümeye dolaylı olarak katkıda bulunulacağı ifade edilmiştir (Ağır, 2010:3-89).

Finansal gelişme ile ekonomik büyüme üzerine yapılan öncü çalışmalarda az gelişmiş ve gelişmekte olan ülkelerin baskınlığı söz konusudur. Bu doğrultuda yapılan çalışmalar, finansal gelişmenin ekonomik büyümenin farklı safhalarında farklı etkiler doğurduğunu göstermektedir. Gelişmiş ülkeler üzerine yapılan çalışmalarda ise finansal sistemdeki kurum ve kuruluşların etkisi ve ürün kompozisyonlarındaki çeşitliliğinin önemi ön plana çıkmaktadır (Afşar, 2007:190-191).

Finansal gelişme ile ekonomik büyüme arasında nedensellik ilişkisi olduğunu ifade eden Partrick (1966) iki kavram arasındaki ilişkiyi, arzın öncüllük ettiği ve talebin takip ettiği nedensellik ilişkisi şeklinde ayrıma tabi tutmuştur (Kar vd., 2014:65). Finansal gelişme ile ekonomik büyüme arasındaki ilişki üzerine kurulan "Arz Öncüllü (İtici) Hipotez", finansal gelişmenin ekonomik büyümeyi arttırıcı yönde etkilediği; "Talep Takipli (Sürükleyici) Hipotez" ise ekonomik büyümenin finansal gelişmenin bir nedeni olduğu görüşüne dayanmaktadır. Arz öncüllü hipoteze göre gelişmiş, istikrarlı ve güvenilir bir finansal yapıya sahip olunması ülke ekonomisinde tasarrufların ekonomiye kazandırılıp, ekonomik büyümenin sağlanmasında son derece önemlidir. Talep takipli hipoteze göre ise, finansal sistemin gelişimi ve sürekliliği için gerekli olan talep artışı ancak ekonomik büyüme ile gerçekleşmektedir. Arz öncüllü (itici) hipotez ile talep takipli hipoteze ek olarak finansal gelişme ve ekonomik büyüme arasındaki nedensellik ilişkisine yönelik olarak ifade edilen bir diğer hipotez ise "Karş1lıklı Etkileşim" yaklaşımıdır. Finansal gelişme ve ekonomik büyüme arasında çift yönlü bir etkileşimin söz konusu olduğunu ifade eden karşıllklı etkileşim hipotezine ters yönde bir görüşü savunan "Etki Yok" hipotezine göre ise, finansal gelişme ile ekonomik büyüme arasında herhangi bir etkileşim söz konusu değildir (Güneş, 2013:75-76).

Yukarıda bahsedilen dört hipotezden Türkiye için hangisinin geçerli olduğunu belirlemeyi amaçlayan bu çalışmanın giriş kısmında, finansal gelişme ve ekonomik büyüme bağlantısına dair genel bilgilere yer verilmiştir. İkinci bölümde ilgili literatür özetlenmiş, üçüncü bölümde araştırma yöntemi, kullanılan veriler ve analiz sonucunda elde edilen bulgulara ilişkin açıklamalar yapılmıştır. Çalışmanın dördüncü bölümünde ise yapılan analiz sonuçlarına yer verilerek çeşitli değerlendirmelerde bulunulmuştur. 


\section{Literatür İncelemesi}

Finansal gelişme ile ekonomik büyüme arasındaki ilişki neo-klasik büyüme modellerinin etkili olduğu 1980'li yılların ikinci yarısına kadar ülkeler arasındaki gelişmişlik düzeyi farklılıkları tam olarak açıklanamadığından göz ardı edilmiştir. Schumpeter (1911) tarafindan finansal hizmetlerin ekonomik büyüme için oldukça önemli olduğunun vurgulanması üzerine finansal gelişme ile ekonomik büyüme arasındaki nedensellik ilişkisinin yönü üzerine yoğunlaşılmıştır. Schumpeter (1911) çalışmasında finansal hizmet ve kuruluşların, üretken yatırımları belirleyip finanse ederek yeniliğin aktif rol aldığı ekonomik büyümeyi destekleme konusundaki öneminin altını çizmiştir (Kar, vd., 2014). Finansal gelişmenin ekonomik büyüme için önemli olduğu görüşü Pagano (1993) başta olmak üzere birçok iktisatçı (Greenwood ve Jovanovic, 1990; Bencivenga ve Smith, 1991; King ve Levine, 1993a, 1993b; Roubini ve Sala-i Martin, 1992;Levine, 1997; Deidda, 2006) tarafından da vurgulanmıştır. Finansal gelişme ile ekonomik büyüme arasındaki ilişkiyi ele alan bir diğer yaklaşım olan McKinnon-Shaw ekolüne göre ise finansal sistemdeki gelişmeler üzerine konulan devlet müdahaleleri ve devletin faiz oran1, rezerv büyüklükleri ve piyasaya giriş hususunda uyguladığı kısıtlamalar finansal gelişmeyi olumsuz etkilemekte ve pozitif reel faiz oranlarıyla tasarrufların teşvik edilerek büyüme oranlarına destek verilmesi gerekmektedir (Aslan ve Küçüksoy, 2006:27; Özşahin, 2011:384).

Finansal gelişme ile ekonomik büyüme üzerine yapılan çalışmalar incelendiğinde genel olarak bir görüş birliği sağlanmadığı ve yapılan çalışmalarda ağırlıklı olarak ekonomik büyüme ve finansal gelişme arasındaki nedensellik ilişkisi üzerine yoğunlaşıldığı görülmektedir. King ve Levine (1993a) çalışmasında 1960-1989 yılları arasında seçilmiş 80 ülkede finansal gelişme ile ekonomik büyüme arasında güçlü bir ilişki olduğu sonucuna ulaşmıştır. Levine (1997) çalışmasında 1960-1989 yılları için seçilmiş 35 ülke üzerine yatay kesit analizi uygulayarak finansal sistem içerisinde yer alan aracı kurumların sayısındaki artışın maliyet avantajı sağlayacağını ve böylece ekonomik büyümeye katkı sağlayacağı ifade etmiştir. Saci ve Holden (2008) çalışmasında 1988-2001 dönemindeki seçilmiş 30 ülke üzerine yapılan panel veri analiz yönteminden faydalanılarak finansal gelişmenin ekonomik büyümeyi hızlandıracağı sonucuna ulaşılmıştır. Hye ve Islam'ın (2013) Bangladeş'deki 1975-2009 yılları arası için uzun ve kısa dönemli finansal gelişme göstergeleri ile ekonomik büyüme arasındaki ilişkinin incelendiği çalışmasında ekonomik gelişme göstergeleri olarak reel faiz oranı ile doğrudan yabancı yatırım parametreleri kullanılmıştır. Çalışmada elde edilen sonuçlar, finansal gelişme göstergeleri olarak kullanılan değişkenler ile ekonomik büyüme arasında uzun ve kısa dönemde negatif yönlü bir ilişki olduğunu göstermektedir. Arestis vd. (2001) Almanya için 1973:1-1997:4, ABD için 1972:2-1998:1, Japonya için 1974:2-1998:1, İngiltere için 1968:2-1997:4, Fransa için ise 1974:1-1998:1 dönemini finans piyasasının gelişimini temsil eden parametrelerden faydalanarak analiz ettikleri çalışmalarında ekonomik büyüme ile finansal gelişme arasındaki ilişkiyi test etmişlerdir. Yapılan çalışmada, piyasa üzerinde bankacılık sistemine dayalı finansal sistemdeki gelişmelerin uzun vadede, borsa işlemlerine dayalı finansal gelişmeden daha yüksek bir oranda pozitif bir etki yaratacağı vurgulanmıştır. Bir başka çalışmada, Ang ve McKibbin (2007), Malezya'daki finansal gelişme ile ekonomik büyüme arasındaki ilişkiyi eşbütünleşme ve nedensellik testleri yardımıyla analiz ederek 1960-2001 yılları arasında finansal serbestleşmenin finans sektörünün gelişimi için itici güç olduğu ve uzun vadede büyümenin finansal derinliği arttırdığı sonucuna ulaşmışlardır. 1982-2012 arası dönemde Hindistan' daki ekonomik büyüme ve finansal gelişme arasındaki ilişkinin analiz edilmesi amacıyla Sehrawat ve Giri (2015) tarafından yapılan çalışmada, arz yönlü hipotezin diğer bir ifadeyle finansal gelişmeden ekonomik büyümeye doğru nedensellik ilişkisinin olduğu tahmin edilmiştir. Pakistan üzerine yapılan Jalil ve Feridun (2011) çalışmasında ARDL 
yönteminden faydalanılarak 1975-2008 yılları arasında ekonomik büyüme ve finansal gelişme arasında pozitif yönlü ilişki olduğu sonucuna ulaşılmıştır. Thangavelu ve Jiunn'in (2004) çalışmasında 1960-1999 dönemi için Avusturalya'da finansal piyasalardaki gelişmenin ekonomik büyümenin nedeni olduğu sonucuna ulaş1lmıştır. Wongpiyabovorn'un (2016) çalışmasında Tayland, Filipin ve Malezya için 1974-2011 yılları arasındaki ekonomik büyüme ve finansal gelişme arasındaki ilişki incelenmiştir. Yapılan çalışmada finansal gelişme ile ekonomik büyüme arasında uzun dönemde ilişki olduğu sonucuna ulaşılmıştır.

Türkiye'de farklı dönemlerdeki finansal gelişme ile ekonomik büyüme arasındaki ilişkinin yönü ve derecesi de birçok çalışma tarafindan incelenmiştir. Kar ve Pentecost'un (2000) çalışmasında 1963-1995 yılları arası için Türkiye'de finansal gelişmeden ekonomik büyümeye doğru bir nedensellik ilişkisi, 1988-2012 dönemleri için Tuna ve Bektaş'1n (2013) çalışmasında yurt içi kredi hacmi ile ekonomik büyüme arasında uzun vadeli ilişki olduğu, Aydın vd. (2014) çalışmasında 1988-2012 yılları arasında finansal gelişmeden ekonomik büyümeye doğru bir nedensellik ilişkisi olduğu sonucuna ulaşılmıştır. Mercan ve Peker'in (2013) çalışmasında, 1992-2010 dönemleri için ARDL yöntemi kullanılarak finansal gelişmeden ekonomik büyümeye doğru nedensellik ilişkisi olduğu sonucuna ulaşılmıştır. Güneş’in (2013) çalışmasında 1988-2009 dönemleri itibarıyla Türkiye'de finansal gelişmenin ekonomik büyümenin, Kandır vd.'nin (2007) çalışmasında ise 1988-2004 yılları arasında Türkiye'deki ekonomik büyümenin finansal gelişmenin nedeni olduğu tahmin edilmiştir. Ak vd. (2016) tarafından da 1989-2011 dönemi itibarıyla Türkiye'de ekonomik büyümeden finansal gelişmeye doğru tek yönlü bir nedensellik ilişkisi olduğu sonucuna ulaşılmıştır. Finansal gelişme ile ekonomik büyüme arasında herhangi bir nedensellik ilişkisinin olmadığı görüşü ise Lucas (1988), Stern (1989) ve Chandavarkar (1992) gibi çalışmalarca desteklenmiştir (Afşar, 2007:196).

Yapılan çalışmalardan elde edilen sonuçlar, finansal gelişme ile ekonomik büyüme arasındaki ilişkinin yönü konusunda ortak bir yargıya ulaşılamadığını göstermektedir. $\mathrm{Bu}$ doğrultuda mevcut çalışmada, en güncel veriler kullanılarak nispeten yeni bir nedensellik analiz yöntemi olan ve Hacker ve Hatemi-J (2006) tarafından geliştirilen Kaldıraçlı (Leveraged) Bootstrap yaklaşımı prosedürü izlenerek finansal gelişme ve ekonomik büyüme ilişkisinin varlığı ve yönüne dair ampirik kanıt sunulması amaçlanmaktadır.

\section{Veri Seti, Yöntem ve Bulgular}

Çalışmanın bu kısmında Türkiye'ye ait 1986-2016 dönemi yıllık zaman serileri kullanılarak finansal gelişme ve ekonomik büyüme arasındaki ilişkinin varlığı ve yönü sorgulanmaktadır. Ekonomik büyümeyi temsilen reel gayrisafi yurtiçi hasıla (GSYH) değişkeni kullanılırken finansal gelişmenin göstergesi olarak dört farklı değişken ele alınmıştır. Kar vd.'nin (2011) çalışması başta olmak üzere ilgili ampirik literatürden yola çıkarak belirlenen finansal gelişme göstergeleri şu şekildedir: i) M3 para arzı büyüklüğünün milli gelire oranı (M3), ii) Finansal sektör tarafindan sağlanan toplam yurt içi kredilerin milli gelire oranı (TYK), iii) Özel sektöre sağlanan toplam yurt içi kredilerin milli gelire oranı (ÖSK), iv) Bankalardaki toplam mevduatın milli gelire oranı (TBM). Çalışmada finansal gelişmeyi temsilen dört farklı göstergenin kullanılmasındaki neden bu değişkenlerle ayrı ayrı analiz yapılarak finansal gelişme ve ekonomik büyüme arasındaki nedensellik ilişkisine dair daha sağlam kanıtların ortaya koyulacağı düşüncesidir. Analiz sürecinde değişen varyans probleminden kaçınmak için tüm değişkenlerin logaritmik değerleri kullanılmıştır. Değişkenlere ait veriler World Bank ve Federal Reserve Economic Data (FRED) veri tabanlarından elde edilmiştir. Değişkenlerin tanımlayıcı istatistikleri Tablo 1'de sunulmuştur. 
Tablo 1: Tanımlayıcı İstatistikler

\begin{tabular}{|c|c|c|c|c|c|}
\hline İstatistikler & GSYH & M3 & TYK & ÖSK & TBM \\
\hline Ortalama & 9,937 & 1,363 & 1,602 & 1,395 & 1,541 \\
\hline Maksimum & 10,216 & 1,707 & 1,909 & 1,847 & 1,909 \\
\hline Minimum & 9,682 & 1,086 & 1,289 & 1,151 & 1,252 \\
\hline Standart Hata & 0,163 & 0,232 & 0,187 & 0,225 & 0,214 \\
\hline Çarp1kl1k & 0,073 & 0,463 & 0,098 & 0,848 & 0,301 \\
\hline Bas1kl1k & 1,812 & 1,485 & 1,801 & 2,248 & 1,664 \\
\hline Jarque-Bera* & 0,396 & 0,131 & 0,385 & 0,108 & 0,249 \\
\hline
\end{tabular}

Serilerin entegre derecelerini belirlemek için Augmented Dickey-Fuller (ADF) t-test ve Phillips-Perron (PP) Z (t $\alpha$ ) testleri uygulanmış ve sonuçlar Tablo 2'de sunulmuştur. ADF ve PP birim kök test sonuçları tüm değişkenlerin seviyede durağan olmadığını, birinci farklarının alınması durumunda durağan hale geldiklerini göstermektedir.

Tablo 2: ADF ve PP Birim Kök Testleri

\begin{tabular}{|c|c|c|c|c|c|}
\hline \multirow{2}{*}{ Değişkenler } & & \multicolumn{2}{|c|}{ ADF } & \multicolumn{2}{c|}{ PP } \\
\cline { 2 - 5 } & & t istatistiği & P* & t istatistiği & P$^{*}$ \\
\hline \multirow{2}{*}{ GSYH } & Seviyede & $-0,274[0]$ & 0,917 & $-0,328[8]$ & 0,976 \\
\cline { 2 - 5 } & Birinci Fark & $-6,629[0]^{*}$ & 0,000 & $-9,123[1]^{*}$ & 0,000 \\
\hline \multirow{2}{*}{ M3 } & Seviyede & $0,132[0]$ & 0,963 & $-0,149[3]$ & 0,935 \\
\cline { 2 - 5 } & Birinci Fark & $-4,69[0]^{*}$ & 0,001 & $-4,634[2]^{*}$ & 0,000 \\
\hline \multirow{2}{*}{ TBM } & Seviyede & $0,094[0]$ & 0,961 & $0,137[2]$ & 0,963 \\
\cline { 2 - 5 } & Birinci Fark & $-5,125[0]^{*}$ & 0,000 & $-5,121[2]^{*}$ & 0,000 \\
\hline \multirow{2}{*}{ OSKK } & Seviyede & $0,673[0]$ & 0,989 & $0,674[0]$ & 0,989 \\
\cline { 2 - 6 } & Birinci Fark & $-4,035[0]^{*}$ & 0,004 & $-4,055[1]^{*}$ & 0,004 \\
\hline \multirow{2}{*}{ TYK } & Seviyede & $-0,099[0]$ & 0,941 & $0,495[14]$ & 0,984 \\
\cline { 2 - 6 } & Birinci Fark & $-5,336[0]^{*}$ & 0,000 & $-5,895[2]^{*}$ & 0,000 \\
\hline
\end{tabular}

Not: *test istatistiklerinin 1\% düzeyinde anlamlı olduğunu göstermektedir. Parantez içerisindeki değerler ADF testinde kullanılan gecikme uzunluklarını gösterirken, köşeli parantez içerisindeki değerler PP testinde kullanılan bant genişliğini göstermektedir.

İki değişken arasındaki nedensellik ilişkisi, bir değişkenin geçmiş değerlerinin VAR modeli çerçevesinde diğer bir değiş̧ken üzerindeki açıklayıcı gücünü ifade eden Granger anlamda nedenselliktir. Granger $(1969,1988)$, Toda-Yamamoto (1995) ve Hacker ve Hatemi-J'nin (2006) geliştirdikleri testler en yaygın kullanılan nedensellik teknikleridir. Çalışmamızda finansal gelişme ve ekonomik büyüme arasındaki nedensellik ilişkisinin test edilmesinde Hacker ve Hatemi-J'nin (2006) geliştirdikleri Bootstrap yaklaşımına dayalı nedensellik tekniği kullanılmaktadır. Efron (1979) tarafından geliştirilen bootstrap tekniği, bir test istatistiğinin dağılımını tahmin etmek için veri setini tekrar tekrar örnekleme dahil etmektedir. Bu tekniği kullanmamızın nedeni testin diğerlerine göre sahip olduğu bazı üstünlüklerinden kaynaklanmaktadır (Hacker ve Hatemi-J, 2006): Standart testler genellikle normallik varsayımına dayalıdır. Bootstrap simülasyon tekniğinde ise hata terimlerinin normal dağılıma sahip olması gibi bir zorunluluk yoktur. Bu tekniğin diğer önemli bir üstünlüğü serilerin durağan olup olmamaları ya da eş bütünleşik olup olmamalarının önemsiz oluşudur. Yine ARCH etkisini dikkate alması bu tekniğin diğer bir üstünlüğü olarak gösterilmektedir. 
Araştırmacıların nedensellik analizlerinde genellikle hata düzeltme modelini ya da geliştirilmiş VAR modeli çerçevesinde Toda-Yamamoto (1995) tekniğini kullandıkları görülmektedir. Geleneksel yöntemlerde Granger nedensellik için test istatistiklerinin asimptotik olarak standart kritik değerleri kullanılmaktadır. Dolayısıyla bir VAR modeli çerçevesinde değişkenlerin birim köke sahip olmaları ya da eş bütünleşik olmaları durumunda Granger nedensellik için hesaplanan test istatistikleri standart asimptotik özelliklere sahip olmayabilir. Toda-Yamamoto (1995), VAR modeli çerçevesinde birim köke sahip olan ya da eş-bütünleşik olan seriler için standart $\chi^{2}$ asimptotik dağılımını garanti eden geliştirilmiş Wald testini (MWALD) ortaya çıkarmıştır. Burada VAR modelinde belirlenen gecikme uzunluğuna serilerin maksimum entegre derecelerine bağlı olarak ekstra bir gecikme uzunluğu $(\mathrm{k}+\mathrm{dmax})$ eklenmektedir. Toda-Yamamoto (1995) yaklaşımına göre tahmin edilen VAR ( $\mathrm{p}+\mathrm{dmax})$ modeli şu şekildedir:

$$
Y_{t}=\alpha_{0}+\sum_{i=1}^{p+d} \alpha_{1(i+d)} Y_{t-(i+d)}+\sum_{i=1}^{p+d} \alpha_{2(i+d)} X_{t-(i+d)}+\sum_{i=1}^{p+d} \alpha_{3(i+d)} X_{t-(i+d)}+\ldots .+\varepsilon_{1 t}
$$

Denklem 1'de $\mathrm{X}$ 'den $\mathrm{Y}$ 'ye doğru bir nedensellik ilişkisi olmadığını ifade eden $\mathrm{H}_{0}$ boş hipotezi $H_{0}: \alpha_{2 i}=0$ şeklinde tanımlanmakta ve buna MWALD testi uygulanmaktadır. $\mathrm{P}$ sayıda serbestlik derecesiyle birlikte asimptotik $\chi^{2}$ dağılımını öngören MWALD test istatistikleri, modeldeki hata terimlerinin beyaz gürültü sürecine sahip olduğunu varsaymaktadır. $\mathrm{Bu}$ varsayım gerçekleşmediğinde ise bu testin geçerliliği ve sağlamlığı sorgulanmaktadır. Hata terimleri normal dağılıma sahip olmadığında ya da ardışık bağlanımlı koşullu değişen varyans (ARCH) etkisi görüldüğünde, MWALD istatistiği $\mathrm{H}_{0}$ boş hipotezini aşırı reddetme eğiliminde olabilmektedir. Bu problemi ortadan kaldırmak için Hacker ve Hatemi-J (2006) kaldıraçlı bootstrap simülasyonlarına dayalı bir test geliştirmişlerdir. Asimptotik $\chi^{2}$ dağılımlarından ziyade bootstrap dağılımlarının kullanılması Toda-Yamamoto test istatistiklerine dayalı daha sağlıklı sonuçlar elde edilmesini sağlamaktadır. Wald testinin özelliklerini bootstrap testi ile karşılaştıran Mantalos (2000), durağan olmayan seriler arasında eş-bütünleşme iliş̧kisi olmasa dahi bootstrap testinin hemen hemen tüm durumlarda daha iyi performans sergilediğini ortaya koymuştur.

Çalışmada Hacker ve Hatemi-J (2006) tarafından geliştirilen bootstrap yaklaşımına dayalı nedenselliği uygulamak için dikkate alınan VAR (p) modeli şu şekildedir:

$$
Y_{t}=\varphi_{0}+\varphi_{1} \mathrm{Y}_{\mathrm{t}-1}+\ldots \ldots \ldots+\varphi_{\rho} \mathrm{Y}_{\mathrm{t}-(\rho+1)}+\varepsilon_{t} \quad \mathrm{t}=1,2, \ldots ., \mathrm{T}
$$

Denklem 2'de $\varepsilon_{t}=\left(\varepsilon_{1 t}, \varepsilon_{2 t}\right)$ sifir ortalamaya sahip bir beyaz gürültü sürecini ifade ederken $p$ modelin gecikme uzunluğunu göstermektedir. VAR modeli çerçevesinde gecikme uzunluğunun seçiminde Schwarz bilgi kriteri baz alınmış ve optimal gecikme uzunluğu 1 olarak bulunmuştur. Bootstrap yönteminde, tahmin sapmalarını azaltmak ve daha güvenilir kritik değerler sağlamak için veri seti tekrar tekrar örnekleme dahil edilmekte ve çalıştırılmaktadır (Hatemi-J, 2002:29). Çalışmamızda MWALD test istatistiğgi dağılımlarını elde etmek için bootstrap simülasyonları $20.000 \mathrm{kez}$ çalıştırılmış ve MWALD test istatistikleri hesaplanmıştır. Elde edilen sonuçlara göre, bootstrap yaklaşımına dayalı MWALD test istatistik değerleri bootstrap kritik değerlerini aşması durumunda nedenselliğin olduğu, aksi durumda ise nedensellik ilişkisinin olmadığı çıkarımında bulunulmaktadır. Bootstrap simülasyon tekniğine dayalı nedensellik testi sonuçları Tablo 3'de sunulmuştur. 
Tablo 3: Bootstrap Simulasyon Tekniğine Dayalı Nedensellik Testi Sonuçları

\begin{tabular}{|c|c|c|c|c|}
\hline Boş Hipotez & $\begin{array}{c}\text { Tahmin Edilen Test } \\
\text { Değeri (MWALD) }\end{array}$ & $\begin{array}{c}\text { 1\% Bootstrap } \\
\text { Kritik Değeri }\end{array}$ & $\begin{array}{c}\text { 5\% Bootstrap } \\
\text { Kritik Değeri }\end{array}$ & $\begin{array}{c}\text { 10\% Bootstrap } \\
\text { Kritik Değeri }\end{array}$ \\
\hline M3 $\neq>$ GSYH & $4,741^{*}$ & 9,147 & 4,598 & 3,043 \\
\hline TYK $\neq>$ GSYH & $3,875^{*}$ & 8,319 & 4,332 & 2,928 \\
\hline ÖSK $\neq>$ GSYH & 0,043 & 8,092 & 4,507 & 3,074 \\
\hline TBM $\neq>$ GSYH & $7,985^{*}$ & 8,072 & 4,402 & 2,968 \\
\hline GSYH $\neq>$ M3 & 1,175 & 9,065 & 4,509 & 2,956 \\
\hline GSYH $\neq>$ TYK & 0,154 & 8,213 & 4,245 & 2,883 \\
\hline GSYH $\neq>$ ÖSK & $3,328^{*}$ & 8,671 & 4,454 & 2,974 \\
\hline GSYH $\neq>$ TBM & 2,413 & 7,831 & 4,305 & 2,944 \\
\hline
\end{tabular}

Not: $\neq>$ notasyonu Granger nedenselliği simgelemektedir. ***, ** ve * notasyonları sırasıyla boş hipotezin \% 1 , $\% 5$ ve $\% 10$ anlamlılık seviyesinde reddedildiğini yani nedensellik ilişkisinin varlığını göstermektedir. VAR modeli gecikme uzunluğu 1 olarak bulunmuş ve değiş̧enlerin maksimum entegre derecesi 1 olduğu için ilave 1 gecikme uzunluğu kullanılmıştır.

Bootstrap simulasyon tekniğine dayalı test sonuçlarına göre özel sektöre sağlanan toplam yurt içi krediler haricindeki diğer üç finansal gelişme göstergesinden ekonomik büyümeye doğru tek yönlü bir nedensellik ilişkisinin olduğu anlaşılmaktadır. Ekonomik büyümenin finansal gelişmeye etkisine dair yapılan analizlerden elde edilen bulgular ise ekonomik büyümenin sadece özel sektöre sağlanan toplam kredi hacmini etkilediği yönündedir. Nedensellik ilişkisinin varlığının sorgulanmasına yönelik yapılan analizden sonra nedensellik ilişkisi bulunan ekonomik büyüklükler arasındaki nedenselliğin yönünü belirlemek amaciyla analizler yürütülmüş ve elde edilen bulgular Şekil 1, 2, 3 ve 4 'te sunulmuştur.

\section{Şekil 1: M3'den GSYH'ye Doğru Nedenselliğin Yönü}

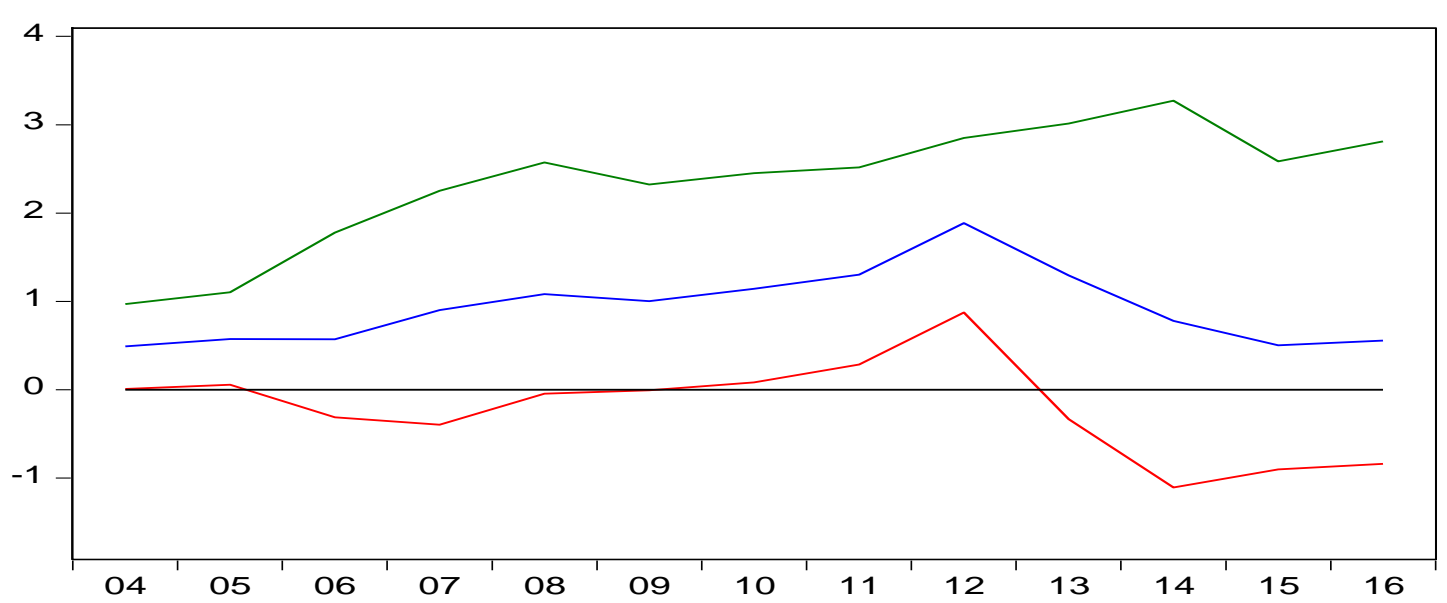

Not: Şekilde üstteki çizgi katsayı toplamlarının üst sınırını gösterirken alttaki çizgi katsayı toplamlarının alt sınırını, ortadaki çizgi ise katsayı toplamlarını göstermektedir. 
Şekil 2: TYK'den GSYH'ye Doğru Nedenselliğin Yönü

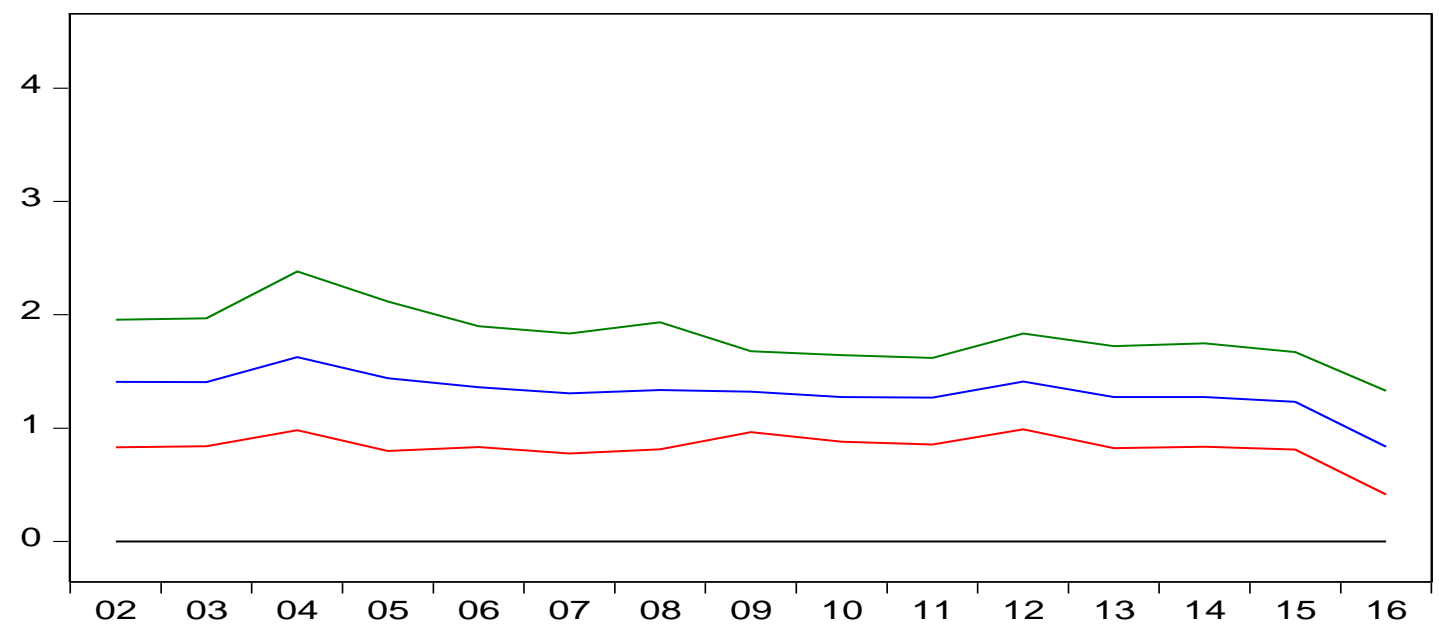

Not: Şekilde üstteki çizgi katsayı toplamlarının üst sınırını gösterirken alttaki çizgi katsayı toplamlarının alt sınırını, ortadaki çizgi ise katsayı toplamlarını göstermektedir.

\section{Şekil 3: TBM'den GSYH'ye Doğru Nedenselliğin Yönü}

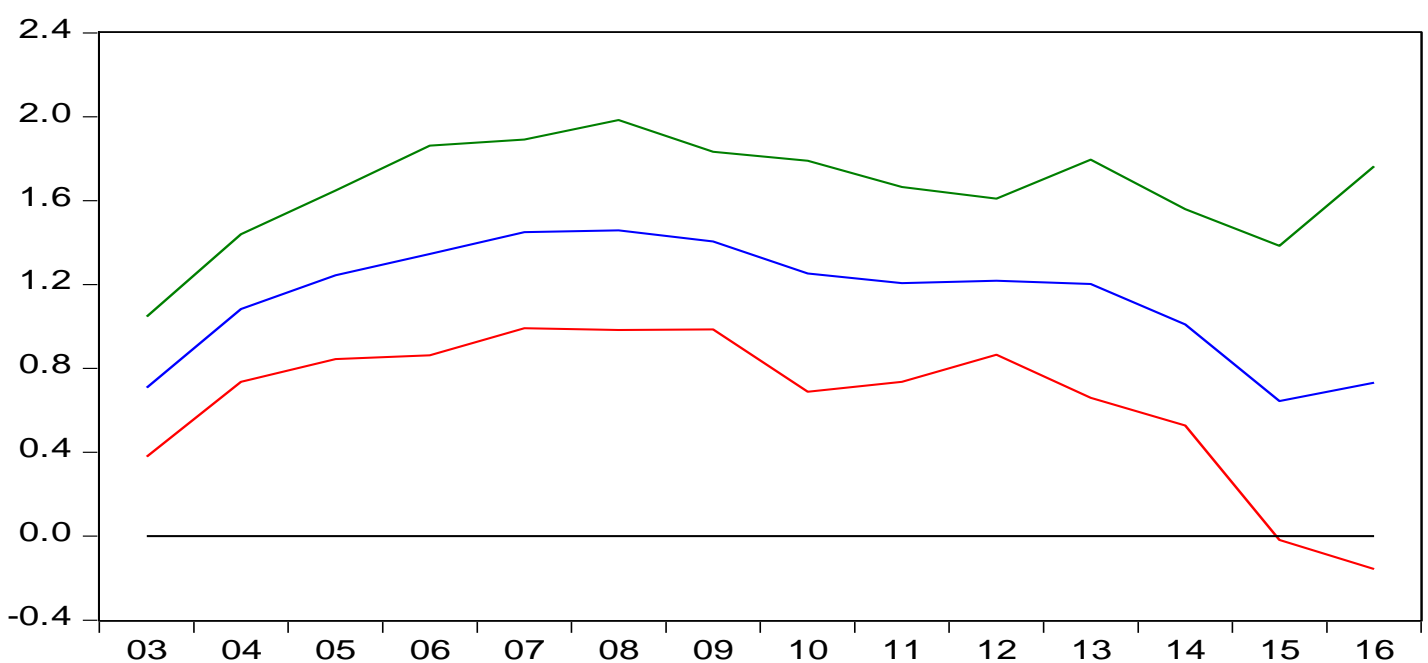

Not: Şekilde üstteki çizgi katsayı toplamlarının üst sınırını gösterirken alttaki çizgi katsayı toplamlarının alt sınırını, ortadaki çizgi ise katsayı toplamlarını göstermektedir. 
Şekil 4: GSYH'den ÖSK'ya Doğru Nedenselliğin Yönü

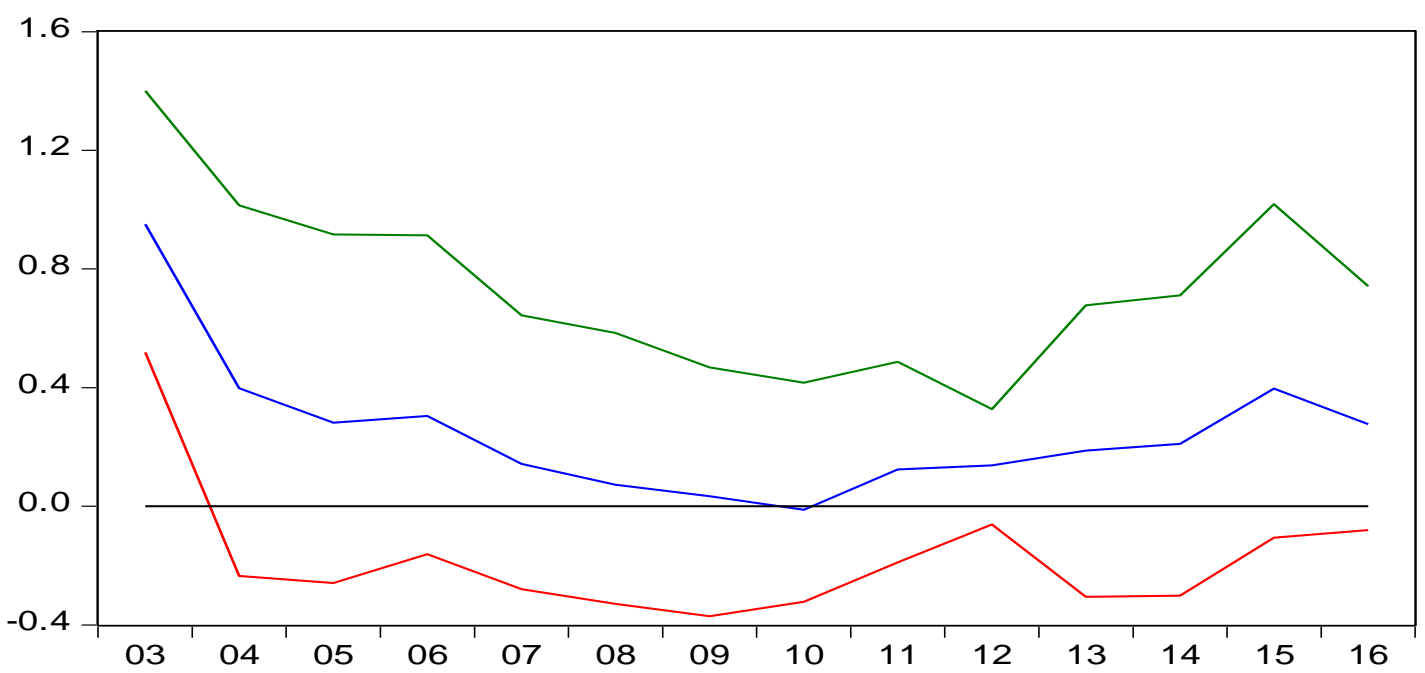

Not: Şekilde üstteki çizgi katsayı toplamlarının üst sınırını gösterirken alttaki çizgi katsayı toplamlarının alt sınırını, ortadaki çizgi ise katsayı toplamlarını göstermektedir.

Analiz bulgularına göre M3 parasal büyüklüğündeki artış, finansal sektör tarafindan sağlanan toplam yurt içi kredilerdeki artış ve toplam banka mevduatlarındaki artışın ekonomik büyümeye etkisi pozitif yöndedir. Yine ekonomik büyümedeki artışın özel sektöre sağlanan toplam yurt içi kredileri pozitif yönde etkilediği (2010 yılı hariç) de elde edilen bir diğer ampirik bulgudur.

\section{Değerlendirme ve Sonuç}

Bu çalışmada Türkiye için 1986-2016 dönemi yıllık zaman serileri kullanılarak finansal gelişme ve ekonomik büyüme arasındaki ilişkinin belirlenmesine yönelik nedensellik analizleri yürütülmüştür. İki değişken arasındaki nedensellik ilişkisinin test edilmesinde Hacker ve Hatemi-J (2006) tarafından geliştirilen Kaldıraçlı (Leveraged) Bootstrap yaklaşımı prosedürü takip edilmiştir. Birden çok ölçütü olan finansal gelişmenin göstergesi olarak çalışmamızda M3 para arzı büyüklüğü, finansal sektör tarafından sağlanan toplam yurt içi krediler, özel sektöre sağlanan toplam yurt içi krediler ve bankalardaki toplam mevduat hacmi büyüklükleri kullanılmıştır. Nedensellik analizlerinden elde edilen bulgulara göre finansal gelişmeyi temsil eden M3 para arzı büyüklüğü, finansal sektör tarafindan sağlanan toplam yurt içi krediler ve bankalardaki toplam mevduat hacminden ekonomik büyümeye doğru tek yönlü bir nedensellik ilişkisi olduğu görülmektedir. Özel sektöre sağlanan toplam yurt içi krediler ve ekonomik büyüme ilişkisine dair nedenselliğin yönü ise ekonomik büyümeden özel sektöre sağlanan toplam yurt içi kredilere doğru tek yönlüdür. Ayrıca bu dört nedensellik ilişkisinin de pozitif yönde olduğu bulgularına ulaşılmıştır. Çalışmadan elde edilen genel sonuçlar ağırlıklı olarak arz öncüllü hipotezi destekler yöndedir. Talep takipli hipotez sadece özel sektöre sağlanan toplam yurt içi kredilerle temsil edilen finansal gelişme göstergesinde destek bulmuştur. Dolayısıyla Türkiye'de finansal gelişmeyi artırmaya dönük uygulamaların ekonomik büyümeye pozitif yönde katkı sunduğu 
ve bu tür uygulamaların kontrollü ve dikkatli bir şekilde geliştirilmesi gerekliliği açıkça ortaya çıkmaktadır.

Elde edilen sonuçlar çerçevesinde, ekonomik büyümeye itici bir güç yaratması amaciyla Türkiye'de finansal gelişme ve derinleşmeye katkı sağlayacak uygulamaların sağlanması ve bu uygulamaların ekonomik koşullara uygun olacak şekilde geliştirilmesi gerektiği açıkça ortaya çıkmaktadır. Bu çerçevede özellikle finansal gelişmenin göstergelerinden, finansal derinliğin sağlanması, özel sektöre verilen kredilerde istikrar sağlanması ve finansal piyasalardaki aracılık maliyetlerinin denetlenmesi gibi düzenlemelerle finansal gelişmenin desteklenmesi gerektiği açıkça ifade edilebilir. 


\section{KAYNAKÇA}

AFŞAR, A. (2007), "Finansal Gelişme İle Ekonomik Büyüme Arasındaki İlişki”, MUFAD Dergisi, 36(3), 102-113.

AĞIR, H. (2010), Türkiye'de Finansal Liberalizasyon ve Finansal Gelişme İlişkisinin Ekonometrik Analizi, BDDK Aroks Doküman Merkezi, Ankara.

AK, M.Z., ALTINTAŞ, N. ve ŞİMŞEK, A.S. (2016), "Türkiye'de Finansal Gelişme ve Ekonomik Büyüme İlişkisinin Nedensellik Analizi”, Doğuş Üniversitesi Dergisi, 17(2), 151-160.

ANG, J.B. ve MCKIBBIN, W.J. (2007), "Financial Liberalization, Financial Sector Development And Growth: Evidence From Malaysia. Journal of Development Economics, 84(1), 215-233.

ARESTIS, P., DEMETRIADES, P. O. ve LUINTEL, K. B. (2001), Financial Development and Economic Growth: The Role of Stock Markets. Journal of Money, Credit and Banking, 33(1), 16-41.

ASLAN, A.G.Ö. ve KÜÇÜKAKSOY, İ. (2006), "Finansal Gelişme ve Ekonomik Büyüme İlişkisi: Türkiye Ekonomisi Üzerine Ekonometrik Bir Uygulama, Ekonometri ve Istatistik Dergisi, (4), 12-28.

AYDIN, M.K., AK, M.Z. ve ALTINTAŞ, N. (2014), "Finansal Gelişmenin Büyümeye Etkisi: Türkiye Özelinde Nedensellik Analiz. Maliye Dergisi, 167, 149-162.

BENCIVENGA, V.R. ve SMITH, B.D. (1991), "Financial Intermediation and Endogenous Growth", Review of Economic Studies 58, 195-209.

CHANDAVARKAR, A. (1992), "Of Finance and Development: Neglected and Unsettled. Questions", World Development, 20(1)

DEIDDA, L.G. (2006), "Interaction Between Economic And Financial Development", Journal of Monetary Economics, 53, 233-248.

EFRON, B. (1979), Bootstrap Methods: Another Look At The Jackknife, The Annals of Statistics, 1-26.

FRED (2017), https://fred.stlouisfed.org/search?st=turkey (Erişim Tarihi: 05.10.2017)

GRANGER, C.W.J. (1969), "Investigating Causal Relations By Econometric Models And Cross Spectral Methods", Econometrica, 37, 424-438.

GRANGER, C.W.J. (1988), "Some Recent Developments In The Concept Of Causality", Journal of Econometrics, 39, 199-211.

GREENWOOD, J. ve JOVANOVIC, B. (1990), "Financial Development, Growth, and the Distribution of Income", Journal of Political Economy 98(5), 1076-1107.

GÜNEŞ, S. (2013), "Finansal Gelişmişlik ve Büyüme Arasındaki Nedensellik Testi: Türkiye Örneği”, Doğuş Üniversitesi Dergisi, 14(1), 73-85.

HACKER, R.S. ve HATEMI-J, A. (2006), "Tests For Causality Between İntegrated Variables Using Asymptotic And Bootstrap Distributions: Theory And Application", Applied Economics, 38(13), 1489-1500.

HATEMI-J, A. (2002), "Export Performance And Economic Growth Nexus İn Japan: A Bootstrap Approach", Japan and the World Economy, 14(1), 25-33.

HYE, Q.M.A. ve ISLAM, F. (2013), "Does Financial Development Hamper Economic Growth: Empirical Evidence From Bangladesh", Journal of Business Economics and Management, 14(3), 558-582.

JALIL, A. ve FERIDUN, M. (2011), "Impact of Financial Development on Economic Growth: Empirical Evidence From Pakistan", Journal of the Asia Pacific Economy, 16(1), 71-80. 
KANDIR, S.Y., İSKENDEROĞLU, A.G. ve ÖNAL, Y.B. (2007), "Finansal Gelişme ve Ekonomik Büyüme Arasındaki İlişkinin Araştırılması", Çukurova Üniversitesi Sosyal Bilimler Enstitüsü Dergisi, 16(2), 311-326.

KAR, M. ve PENTECOST, E.J. (2000), "The Direction of Causality Between Financial Development and Economic Growth in Turkey: Further Evidence”, Loughborough University, Department of Economics, Economic Research Paper No: 00/27.

KAR, M., NAZLIOĞLU, Ş. ve AGIR, H. (2011), "Financial Development And Economic Growth Nexus in The MENA Countries: Bootstrap Panel Granger Causality Analysis", Economic Modelling, 28(1), 685-693.

KAR, M., NAZLIOGLU, Ș. ve AGIR, H. (2014). "Trade Openness, Financial Development and Economic Growth in Turkey: Linear and Nonlinear Causality Analysis". Journal of BRSA Banking \& Financial Markets, 8(1).

KING, R.G. ve LEVINE, R. (1993a), Finance and Growth: Schumpeter Might Be Right? Quarterly Journal of Economics 108(3), 717-737.

KING, R.G. ve LEVINE, R. (1993b), "Finance, Entrepreneurship, and Growth: Theory and Evidence", Journal of Monetary Economics, 32 (3), 513-542.

LEVINE, R. (1997), "Financial Development and Economic Growth: Views and Agenda", Journal of Economic Literature, 35, 688-726.

LUCAS, R.E. (1988), "On the Mechanics of Economic Development”, Journal of Monetary Economics, 22(1), 3-42.

MANTALOS, P. (2000), "A Graphical İnvestigation of the Size and Power of the GrangerCausality Tests In Integrated-Cointegrated VAR Systems", Studies in Nonlinear Dynamics and Econometrics, The MIT Press, 4(1), 1-18.

MERCAN, M. ve PEKER, O. (2013), "Finansal Gelişmenin Ekonomik Büyümeye Etkisi: Ekonometrik Bir Analiz", Eskişehir Osmangazi Üniversitesi İktisadi ve İdari Bilimler Dergisi, 8(1), 93-120.

ÖZŞAHIN, Ş. (2011), "Türkiye Ekonomisinde Finansal Liberalizasyon ve Ekonomik Büyüme Etkileşimi Üzerine Ekonometrik Bir Analiz (Doktora Tezi,, Selçuk Üniversitesi Sosyal Bilimleri Enstitüsü).

PAGANO, M. (1993), "Financial Markets and Growth: An Overview", European Economic Review, 37, 613-622.

PATRICK, H.T. (1966), "Financial Development and Economic Growth in Underdeveloped Countries". Economic Development and Cultural Change, 14, 174-189

ROUBINI, N. ve SALA-I MARTIN, X. (1992), "Financial Repression and Economic Growth. Journal of Development Economics 39, 5-30.

SACI, K. ve HOLDEN, K. (2008), "Evidence on Growth and Financial Development Using Principal Components", Applied Financial Economics, 18(19),1549-1560.

SCHUMPETER, J.A. (1911), "The Theory of Economic Development; an Inquiry into Profits, Capital, Credit, Interest, and the Business Cycle, Translated by Opie", R. Harvard University Press, Cambridge.

SEHRAWAT, M. ve GIRI, A.K. (2015), "Financial Development and Economic Growth: Empirical Evidence From India", Studies in Economics and Finance, 32(3), 340356.

STERN, N. (1989), "The Economics of Development: A Survey", The Economic Journal, $100,597-685$.

THANGAVELU, S.M. ve JIUNN, A. B. J. (2004), "Financial Development and Economic Growth In Australia: An Empirical Analysis", Empirical Economics, 29(2), 247280. 
TODA, H.Y. ve YAMAMOTO, T. (1995), "Statistical Inference in Vector Autoregressions With Possibly Integrated Processes", Journal of Econometrics, 66, 225-250.

TUNA, K. ve BEKTAS, H. (2013), "Kredi Hacminin Ekonomik Büyüme Üzerindeki Rolünün Incelenmesi: Türkiye Örneği”, Finansal Araştırmalar ve Çalışmalar Dergisi, 5(9), 139-150.

WONGPIYABOVORN, O. (2016), "Financial Development and Economic Growth: The Cases of Thailand, Malaysia, and the Philippines", International Journal of Economic Policy in Emerging Economies, 9(2), 103-126.

FRED (2017), https://fred.stlouisfed.org/ (Erişim Tarihi: 22.09.2017).

WORLD BANK (2017), http://databank.worldbank.org/data/reports.aspx?source=worlddevelopment-indicators\# (Erişim Tarihi: 14.09.2017). 